\title{
Paradoxo do direito vigente de Ross
}

\author{
The valid law paradox of Ross
}

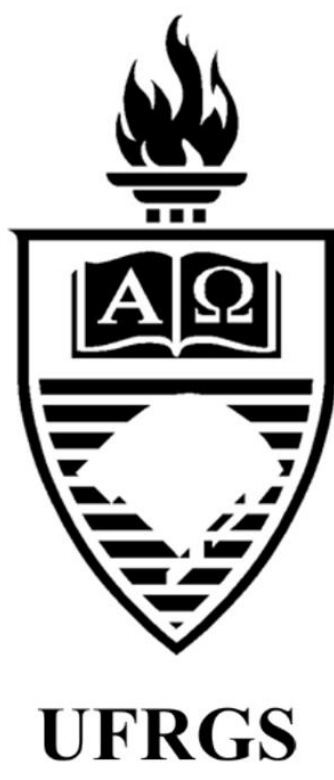

Dafne Reichel Cabral

Universidade Federal de Mato Grosso do Sul

Flávio Garcia Cabral

Centro Universitário Anhanguera de Campo

Grande - Unidade 1 - UNAES 


\title{
Paradoxo do direito vigente de Ross
}

\author{
The valid law paradox of Ross
}

Dafne Reichel Cabral*

\author{
Flávio Garcia Cabral ${ }^{* *}$
}

\section{REFERÊNCIA}

CABRAL, Dafne Reichel; CABRAL, Flávio Garcia. Paradoxo do direito vigente de Ross. Revista da Faculdade de Direito da UFRGS, Porto Alegre, n. 34, p. 118-130, ago. 2016.

\section{RESUMO}

Trata-se de paper que possui como objetivos precípuos o escrutínio do trabalho do jurista dinamarquês Alf Ross, abordando com maior precisão a sua análise do Direito, em especial da vigência do ordenamento jurídico, demonstrando, assim, como, de forma peculiar, a vigência do ordenamento em Ross constitui um verdadeiro paradoxo com a estabilidade social de determinada sociedade.

\section{PALAVRAS-CHAVE}

Alf Ross. Paradoxo. Direito Vigente.

\section{ABSTRACT}

It is a paper that has as its main goals the scrutiny of the work of the Danish jurist Alf Ross, approaching more precisely his analysis of the Law, especially the validity of the legal system, thereby demonstrating how, in a peculiar way, the validity of the system in Ross constitutes a real paradox with the social stability of a certain society.

\section{SUMÁRIO}

Introdução. 1. O paradoxo deôntico de Ross. 2. Direito vigente. 3. O paradoxo do direito vigente de Ross. Conclusão. Referências.

\section{INTRODUÇ̃̃O}

Nascido em Copenhague, Dinamarca, em 10 de junho de 1889, Alf Niels Christian Ross

\section{KEYWORDS}

Alf Ross. Paradox. Valid Law.

\footnotetext{
* Mestranda em Direito Humanos (Universidade Federal de Mato Grosso do Sul - UFMS). Especialista em Direito Tributário (Instituto Brasileiro de Estudos Tributários - IBET, 2012). Especialista em Direito Administrativo (Pontifícia Universidade Católica de São Paulo, PUC/SP, 2013). Graduada em Direito (Universidade Anhanguera - UNIDERP, 2009). Auditora de Controle Externo do Tribunal de Contas do Estado de Mato Grosso do Sul - TCE/MS.

** Professor de Direito Administrativo (Centro Universitário Anhanguera de Campo Grande - Unidade 1 - UNAES). Doutorando em Direito Administrativo (Pontifícia Universidade Católica de São Paulo - PUC/SP). Mestre em Direito (Universidad de Girona - UDG, Espanha, 2014). Mestre em Direito Constitucional (Pontifícia Universidade Católica do Rio de Janeiro - PUC/RJ, 2011). Especialista em Direito Administrativo (Pontifícia Universidade Católica do Rio de Janeiro - PUC/RJ, 2013). Graduado em Direito (Universidade Federal de Mato Grosso do Sul - UFMS, 2009). Procurador da Fazenda Nacional - PFN.

${ }^{1}$ Importante atentar-se que a escola realista de Ross não se confunde com o chamado realismo norte-americano, representado precipuamente pelo pragmatismo extremado de Oliver Wendell Holmes Jr.. Para maiores considerações, confira-se HOLMES JR., Oliver Wendell. The Common Law. New York: Dover, 1991.
} 
como Lundstedt, Ofstad, Jorgensen, Hägerström, dentre outros. Possuiu duas grandes influências precípuas na sua vida e obra, mencionando-se o sueco, fundador da escola de Uppsala, Axel Hägeström, de quem Ross foi aluno e assimilou um conceito "materialista da realidade e as tendências de crítica filosófica da linguagem", e também o jurista de Viena, Hans Kelsen, de onde se herda, apesar de inúmeras críticas ${ }^{3}$, elementos essenciais da teoria pura do Direito.

Dentre a vasta produção bibliográfica de Ross, podemos destacar como as principais a "Teoria das Fontes do Direito", de 1929; "Para uma ciência realista do Direito", do ano de 1946; "Direito e Justiça", datada de 1953 e 1958; "Lógica das Normas", de 1967; e "Direito Constitucional Dinamarquês", dividido em dois volumes, referente ao ano de 1958.

Outrossim, é sabido que Ross se dedicou a diversas áreas do direito, como sua teoria geral e filosofia - talvez o que lhe deu mais reconhecimento -, mas também ao direito privado, direito internacional (inclusive tendo servido como juiz da Corte Europeia de Direitos Humanos de 1959 a 1972), direito constitucional e direito penal. ${ }^{4}$

$\mathrm{O}$ autor dinamarquês, na sua construção da doutrina realista, rivaliza com os métodos de estudo do Direito realizados tanto pela chamada escola jusnaturalista, ou jusfilosofia axiológica, desenvolvida dos sistemas de Kant e Hegel, por exemplo, bem como da escola analítica do direito, capitaneada por John Austin e Hans Kelsen, dentre outros. ${ }^{5}$

Não obstante toda obra de Alf Ross possua elementos interessantes e instigantes a se

\footnotetext{
${ }^{2}$ ROSS, Alf. Direito e Justiça. Tradução Edson Bini. 2. ed. Bauru: EDIPRO, 2007.

${ }^{3}$ Sobre as críticas de Ross a Kelsen confira-se DELGADO PINTO, José. Sobre la vigencia y la validez de las normas jurídicas. Doxa, Alicante, n. 07, p. 101-167, 1990.

${ }^{4}$ Para uma análise completa da biografia de Alf Ross, confira-se WAABEN, Knud. Alf Ross 1899-1979: A Biographical Sketch. European Journal of International Law, v. 14.4, p. 661-674, 2003.
}

desenvolver uma pesquisa, conforme se pode inclusive presumir do breve escorço histórico que se mostrou pertinente, a fim de compreender, ainda que de sorte perfunctória, a origem e influências sociais e doutrinárias de Ross, insta indicar que neste paper será realizada uma abordagem mais restrita do trabalho do jurista de Copenhague.

Assim, relevante alertar que os limites deste trabalho não percorrem toda a obra de Ross, analisando-se com afinco toda sua construção intelectual. Estar-se-á adstrito ao estudo do entendimento de Ross sobre a vigência das normas no ordenamento jurídico, principalmente como foi exposto de forma brilhante na obra "Direito e Justiça", para, posteriormente, poder-se vislumbrar a capacidade de Ross ao criar uma condição para a vigência que seja paradoxal à estabilidade de uma ordem social.

De igual forma, se abordará, ainda que em termos superficiais, um segundo paradoxo de Ross - que cronologicamente antecede o paradoxo exposto na obra "Direito e Justiça" -, pertinente à lógica deôntica, destacado em seu artigo "Imperatives and Logic", publicado em 1941, que não possui relação com o tema principal deste trabalho, mas que merece ser destacado, a fim de que não haja imbróglios indevidos ao se vislumbrar o termo "paradoxo de Ross".

\section{O PARADOXO DEÔNTICO DE ROSS}

A expressão "paradoxo de Ross" encontrase mais comumente associada ao paradoxo ${ }^{6}$ da lógica deôntica - apresentado por Ross, em 1941,

\footnotetext{
${ }^{5}$ ROSS, Alf. Direito e Justiça. Tradução Edson Bini. 2. ed. Bauru: EDIPRO, 2007. p. 24-26.

${ }^{6}$ Curiosamente há ainda um terceiro paradoxo de Ross, invocado por Cesar Antônio Serbena (Paradoxos semânticos e auto-referência normativa na linguagem jurídica. In: VII Congresso Brasileiro de Filosofia, 2002, João Pessoa-PB. VII Congresso Brasileiro de Filosofia Anais. João Pessoa-PB, 2002. v. único. p. 364), que seria aquele "formulado para o caso das normas de uma
} 
no artigo "Imperatives and Logic", e posteriormente reiterado na obra "Directives and Norms" de 1967 - do que assumindo a feição paradoxal abordada neste trabalho concernente à vigência normativa e à estabilidade da ordem jurídica. Precisamente por isto, faz-se de suma importância diferenciar ambos os paradoxos, apontando que o deôntico será abordado en passant, tendo em vista não constituir o presente objeto de estudo, servindo somente como paradigma para que não haja confusões ao se referir às asserções de Ross.

Adentrando o universo da lógica, que pode ser entendida em grossos termos como "a disciplina que investiga os princípios da argumentação válida" ${ }^{7}$, ver-se-á que o ramo da lógica deôntica - comumente definida como a lógica da obrigação, permissão ou proibição ${ }^{8}$-, cujos grandes expoentes são o austríaco Ernst Mally e o finlandês Georg Henrik Von Wright, possui sistemas-padrão (Standard Deontic Logic - SDL) - atribuídos especialmente por Von Wright - que, inicialmente, Ross se mostrou cético quanto a sua validade lógica, tendo demonstrado, inclusive, um paradoxo derivado do "princípio de consequência deôntica" ${ }^{9}$ a fim de evidenciar a

Constituição que regulam o procedimento especial para a reforma da própria Constituição. Elas são ao mesmo tempo normas que estabelecem uma autoridade constituinte distinta da autoridade legislativa".

${ }^{7}$ GOMES, Nelson Gonçalves. Um panorama da lógica deôntica. Kriterion: Revista de Filosofia, Belo Horizonte, v. 49, n. 117, 2007, p. 9.

${ }^{8}$ A definição de lógica deôntica, assim como qualquer definição de relevo, apresenta-se por demais turbulenta. Conforme assevera Macnamara (Deontic Logic. In:. GABBAY, Dov M.; WOODS, John (Org.). Handbook of the history of logic: Logic and the modalities in the Twentieth Century - v. 7. Amsterdã: Elsevier Science \& Techonology Books, 2006. p. 198), a conceituação normalmente atribuída à lógica deôntica padece da problemática de ser muito restrita ou muito abrangente, não compreendendo seus reais propósitos e objetos. A descrição apresentada no corpo do texto seria o que aquele autor considera muito restrita, por excluir muitos elementos, contudo, preferível sua utilização neste trabalho com o fim meramente ilustrativo da significação de lógica deôntica.

9 TESTA, Rafael Rodrigues. Uma análise de algumas lógicas deônticas para a representação de normas inaplicabilidade de um sistema padrão da lógica deôntica.

A questão em que Ross se debruça nas páginas de "Imperatives and logic" reside em saber se um imperativo incondicional pode ser tanto uma premissa como a conclusão de uma inferência lógica. ${ }^{10}$

Assim, o sistema padrão tido como válido, mas posto em conflito por Ross, reside na formulação representativa de $\mathrm{O} p \supset \mathrm{O}(p \mathrm{~V} q) .^{11}$ Ross, portanto, propõe paradoxalmente que se suponha que $\mathrm{O} p$ seja enviar uma carta e a simbologia $\mathrm{O}(p \mathrm{~V} q)$ signifique enviar uma carta (p) ou queimá-la (q). Logo, havendo a obrigação de enviar uma carta (Op), haveria de igual forma a obrigação de enviar uma carta ou de queimá-la ("slip the letter into the letter-box! We may infer, slip the letter into the letter-box or burn it"12).

A situação é evidentemente paradoxal, pois o ato que permite cumprir com a segunda obrigação admite que se queime a carta, muito embora esse mesmo ato não seja adequado para atender a primeira obrigação, qual seja, a de enviar carta. ${ }^{13}$ É justamente nesse ponto a inquietação de Ross, uma vez que embora a construção lógica $\mathrm{O} p \quad \supset \quad \mathrm{O}\left(\begin{array}{llll}p & \mathrm{~V} & q\end{array}\right)$ seja

jurídicas. Campinas: Universidade Estadual de Campinas, 2006. p. 28.

${ }^{10}$ HEMPEL, Carl G. Review: Imperatives and logic by Alf Ross. The Journal of Symbolic Logic, New York, v.6, n. 3, 1941. p. 106.

${ }^{11}$ A simbologia utilizada consiste em operadores lógicos com significações diversas, podendo-se mencionar, como

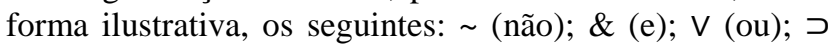
(se..., então...); $\forall$ (para todo); $\exists$ (existe ao menos um), etc. 12 ROSS, Alf. Imperatives and Logic. Philosophy of Science, Chicago, v. 11.1, 1944. p. 38.

${ }^{13}$ Embora a pretensão desse artigo não seja confirmar ou infirmar o paradoxo da lógica deôntica trazido por Ross, calha indicar que, segundo Gomes, não se estaria em realidade diante de um paradoxo, porquanto "a obrigação de realizar $\mathrm{p}$ ou q vem antecedida pela obrigação de realizar $\mathrm{p}$, de modo que não existe a possibilidade de escolha entre pôr a carta no correio ou queimá-la" (GOMES, Nelson Gonçalves. Um panorama da lógica deôntica. Kriterion: Revista de Filosofia, Belo Horizonte, v. 49, n. 117, 2007. p. 14). 
naturalmente expressa, ao se preencher seus conteúdos deônticos ocorre o paradoxo apontado.

Deveras, o autor dinamarquês expõe em "Imperatives and logic" que se o primeiro imperativo é satisfeito, ou seja, a carta foi enviada, então o segundo imperativo também foi satisfeito (é verdade que a carta foi enviada ou foi queimada). Contudo, prossegue, é óbvio que essa inferência não pode ser imediatamente concebida como logicamente válida. ${ }^{14}$

A crítica de Ross reside no que ele denomina "lógica da satisfação", onde se infere que um valor lógico de estar satisfeito transferese das premissas para a conclusão. Assim, qualquer sentença que satisfizesse a premissaimperativa satisfaria também a conclusão imperativa. ${ }^{15}$ Nesta medida, com a demonstração da hipótese do envio da carta, Ross expõe, através de um paradoxo, que a lógica da satisfação é insuficiente, pois pode vir a se mostrar como falsa. Para o autor, embora certas premissas possam ser válidas na "lógica da satisfação", não são intuitivamente aceitáveis. Sobre a questão, merece transcrição a seguinte passagem:

\begin{abstract}
Nuestro sentimiento de evidencia no se refiere a la satisfacción del directivo, sino más bien a algo así como su 'validez', 'existencia' o 'vigencia' comoquiera que se entiendan estas expresiones -. Que una lógica de la satisfacción es inadecuada en cuanto reconstrucción de nuestro razonamiento práctico resulta claro del hecho de que la negación, la disyunción y la implicación deónticas internas, como se ha mostrado en las secciones precedentes de este capitulo, tienen peculiaridades que las distinguen de las correspondientes funciones en la lógica indicativa. Esta divergencia se ve en inferencias que son válidas en la lógica de la satisfacción, pero que no son intuitivamente aceptables. ${ }^{16}$
\end{abstract}

\footnotetext{
14 ROSS, Alf. Imperatives and Logic. Philosophy of Science, Chicago, v. 11.1, 1944. p. 38.

${ }^{15}$ HEMPEL, Carl G. Review: Imperatives and logic by Alf Ross. The Journal of Symbolic Logic, New York, v. 6, n. 3, 1941. p. 106.

${ }^{16}$ ROSS, Alf, Logica de las normas. Tradução José S.P. Hierro. Madrid: Editorial Tecnos, 1971. p. 162.
}

Contudo, não é sobre esse primeiro paradoxo - talvez o que possua maior evidência, pelo menos na área dos estudos lógicos - que iremos cuidar com mais cautela, mas sim o que remete ao conceito de direito vigente para Alf Ross.

\section{DIREITO VIGENTE}

Retomando o estudo central deste trabalho, deve-se analisar a conceituação de Ross para o que chama de "direito vigente", a fim de compreender suas nuances e particularidades.

Buscando esclarecer a noção de direito vigente, Alf Ross se propõe inicialmente a fazer um comparativo entre o Direito, entendido como "ordenamento jurídico", e um jogo de xadrez. ${ }^{17}$ "Sua tese é que as normas jurídicas, como as regras de um jogo de xadrez, atuam como 'esquemas de interpretação' para um conjunto de 'atos sociais' tornando possível a compreensão das 'ações sociais'."18

Inicia Ross supondo a observância de uma partida de xadrez por um terceiro. Segundo o autor, caso o observador não conheça as regras de um jogo de xadrez, aquele "não compreenderá o que está se passando"19, soando como uma série de movimentos desconexos e sem significação. Por outro lado, adquirirá um caráter distinto caso o observador tenha conhecimento sobre as regras do jogo, situação na qual passará a compreender e reconhecer os movimentos como "prescritos pelas regras", sendo capaz, inclusive, com certas limitações, de predizer jogadas futuras, dada a

\footnotetext{
${ }^{17}$ É o que Garcia Máynez chama de "concepção lúdica do direito" (GARCIA MÁYNEZ, Eduardo. En torno de la Teoria de Alf Ross. Crítica: Revista Hispanoamericana de Filosofía, Mexico, vol. 1, n. 3, sep. 1967. p. 6).

${ }^{18}$ SGARBI, Adrian. Clássicos de Teoria do Direito. 2. ed. Rio de Janeiro: Lumen Juris, 2009. p.71.

${ }^{19}$ ROSS, Alf. Direito e Justiça. Tradução Edson Bini. 2. ed. Bauru: EDIPRO, 2007, p.34.
} 
predisposição das peças no tabuleiro em conjunto com as regras existentes. ${ }^{20}$

Justamente ao tratar sobre as "regras do xadrez", Ross se refere às suas regras primárias, entendendo-as como as que "determinam a disposição das peças, os movimentos, a 'tomada', etc." 21 , sendo encaradas como verdadeiras diretivas $^{22}$, indicando como o jogo (xadrez) deve ser jogado.

Surge então o questionamento: como seria possível se estabelecer quais as regras que norteiam a partida de xadrez?

Ross começa a responder à referida pergunta excluindo a utilização do simples observar externo, sob o "ângulo comportamental", como meio adequado a aferir quais as regras buscadas. ${ }^{23}$ Escrutinar o jogo de xadrez em busca de suas regras por meio de uma análise comportamental _ cmodelo condutivista" 24 - não seria correto, porquanto, por vezes, se confundiriam meros hábitos condicionados pela teoria do jogo com as regras vigentes.

Seria mais prático, então, orientar-se por determinados regulamentos emitidos por autoridades, ou dados constantes de obras que possuam reconhecimento, para se poder compreender as regras do jogo de xadrez. Embora possa aparentar maior valor que o "aspecto comportamental" acima exposto, Ross enxerga que este método ("modelo formalista" 25 ) utilizado solitariamente também apresenta suas imperfeições, restando insuficiente, pois "não é certo que tais declarações recebam adesão na prática" ${ }^{26}$, ou seja, que o jogo se conduza daquela forma prescrita. Portanto, conclui que é

\footnotetext{
${ }^{20}$ ROSS, Alf. Direito e Justiça. Tradução Edson Bini. 2. ed. Bauru: EDIPRO, 2007. p. 35.

${ }^{21}$ Ibid, p. 37.

${ }^{22}$ Ross diferencia as expressões linguísticas em expressões de asserção (são aquelas com significado representativo), exclamações (sem significado representativo e sem intenção de exercer influência) e diretivas (expressões com a intenção de exercer influência, mas sem significado representativo) (ROSS, op. cit., p. 31).
}

necessário saber as regras que regem uma partida realizada por dois jogadores em uma situação concreta, já que são "suas ações, e suas ações exclusivamente, aquelas que estão aglutinadas num todo significativo e regidas pelas regras". ${ }^{27}$

Deste modo, acrescenta Ross outro método a ser adotado, isto é, a forma introspectiva. O que se deve revelar, assim, é quais regras são sentidas pelos jogadores de uma partida de xadrez como socialmente obrigatórias, ou seja, motivadoras. Logo, dois momentos fazem-se presentes na aferição das regras de xadrez. Primeiro tem-se como critério determinante que elas "sejam realmente efetivas no jogo e sejam externamente visíveis como tais". Contudo, para se saber se indigitadas regras são acatadas ou não, deve-se, posteriormente, "indagar aos jogadores por quais regras se sentem obrigados". ${ }^{28}$

Após a análise sustentada por Ross, alcança-se o resultado de que uma regra de xadrez pode ser tida como vigente se dentro de uma dada coparticipação (que compreende fundamentalmente os dois jogadores de uma partida concreta) essa regra recebe efetiva adesão, porque os jogadores sentem a si mesmos socialmente obrigados pela diretiva contida na regra. $^{29}$

Ross, então, utilizando-se do conceito de regra vigente de xadrez como paradigma para o entendimento de direito vigente, constrói, nos mesmos termos do primeiro, a significação do segundo como sendo um conjunto abstrato de ideias normativas que serve como um esquema interpretativo para os fenômenos do direito em ação, o que por sua vez significa que essas normas são efetivamente acatadas e que o são porque são

\footnotetext{
${ }^{23}$ Ibid, p. 38.

${ }^{24}$ SGARBI, Adrian. Teoria do Direito: primeiras lições.

Rio de Janeiro: Lumen Juris, 2007, p. 325.

${ }^{25}$ Ibid, p. 325.

${ }^{26}$ ROSS, Alf. Direito e Justiça. Tradução Edson Bini. 2. ed.

Bauru: EDIPRO, 2007, p. 38.

${ }^{27}$ Ibid, p. 38.

${ }^{28}$ Ibid, p. 39

${ }^{29}$ Ibid, p. 39.
} 
experimentadas e sentidas como socialmente obrigatórias. $^{30}$

Neste diapasão, conforme se verifica, Ross afasta um entendimento do direito vigente como sendo aquele completamente no patamar da realidade, e exclusivamente nela, da mesma forma que rejeita a exclusividade do "mundo das ideias". Destarte, o autor escandinavo descarta a utilização extremada somente do "método formalista" ou unicamente do método condutivista. ${ }^{31}$

Buscando enriquecer e tornar mais inteligível a figura do direito vigente, Ross sugere duas novas indagações que merecem ser resolvidas: 1) como seria possível diferenciar um corpo individual de normas entendidas como um ordenamento jurídico nacional de outros corpos individuais, a exemplo do próprio xadrez? 2) Se um sistema de normas pode servir como esquema interpretativo, como aplicar esse critério ao direito? ${ }^{32}$

Deve-se esclarecer que para cumprir o proposto neste trabalho, resta suficiente, por ora, uma abordagem somente do primeiro questionamento, mas, deixando claro que um entendimento completo da construção rossoniana exige a passagem por ambas as perguntas, sendo certo que a escolha somente de uma delas constitui mera discricionariedade metodológica, a fim de não se alargar em demasia o objeto do presente estudo.

Dessa maneira, a resposta à primeira pergunta de Ross pode ser obtida visitando-se três pontos: quais as normas que compõem uma

\footnotetext{
${ }^{30}$ ROSS, Alf. Direito e Justiça. Tradução Edson Bini. 2. ed. Bauru: EDIPRO, 2007, p. 41.

${ }^{31}$ SGARBI, Adrian. Clássicos de Teoria do Direito. 2. ed. Rio de Janeiro: Lumen Juris, 2009, p. 74.

${ }^{32}$ ROSS, op. cit., p. 54.

${ }^{33}$ SGARBI, op. cit., p. 75.

${ }^{34}$ ROSS, op. cit., p. 57.

${ }^{35}$ Ibid, p. 57.

${ }^{36}$ Em realidade o termo é ainda mais amplo para Ross, incluindo também as autoridades encarregadas da prevenção e punição de crimes como a polícia e Ministério Público, por exemplo (ROSS, op. cit., p. 60).
}

ordem jurídica nacional, a quem elas são dirigidas e qual a sua significação. ${ }^{33}$

Quanto às normas que estruturam uma ordem jurídica, Ross as divide, de acordo com seu conteúdo imediato, em dois tipos: "normas de conduta" e "normas de competência". 34

Enquanto as normas de condutas seriam aquelas que ditariam uma determinada "linha de ação", as normas de competência seriam criadoras de poder, autoridade. As normas de competência poderiam ser encaradas como "normas de conduta expressas indiretamente". Aclarando a questão, Ross exemplifica as normas de competência da seguinte forma: "As normas da Constituição concernentes à legislatura, por exemplo, são normas de conduta expressas indiretamente que prescrevem comportamento de acordo com as normas ulteriores de conduta que sejam criadas por via legislativa". 35

No que concerne ao destinatário da norma talvez um dos grandes pontos característicos da obra de Ross -, entende este serem os tribunais ${ }^{36}$, compreendidos num sentido abrangente, incluindo todo o grupo de magistrados de um país. ${ }^{37}$ Ross assenta que "uma medida legislativa que não encerre diretivas para os tribunais só pode ser considerada como um pronunciamento ideológico-moral sem relevância jurídica". ${ }^{38}$

Entende Ross que as regras como diretivas voltadas aos tribunais permitem que elas próprias, sem necessidade de informações adicionais, sejam suficientes aos particulares, que terão nas esperadas reações dos tribunais uma diretriz em

\footnotetext{
${ }^{37}$ Fazendo uma crítica a essa questão em Ross, declaram Frank e Correa (FRANK, Felipe; CORRÊA, Rafael. Direito e Justiça Segundo o Realismo Jurídico de Alf Ross. ANIMA: Revista Eletrônica do Curso de Direito das Faculdades OPET - Caderno de produção do corpo Docente e Discente, Curitiba, n. 13, jan./jun. 2015): "Vale destacar que essa realidade dos fatos, na teoria rossoniana, refere-se à conduta dos juízes, sendo, portanto, um fato social bastante delimitado, que não se reporta diretamente à sociedade como um todo e à sua pluralidade de práticas sociais." ${ }^{38}$ ROSS, op. cit., p. 57.
} 
como se deve conduzir. ${ }^{39}$ Desta feita, utilizandose do exemplo invocado por Ross, ao proibir-se o aborto criminoso, pode-se retirar a seguinte conclusão:

[...] [O] verdadeiro teor do direito consistirá numa diretiva para o juiz segundo a qual ele deverá, sob certas condições, impor uma pena por aborto criminoso. $\mathrm{O}$ fator decisivo que determina que a proibição é direito vigente é tão-somente o fato de ser efetivamente aplicada pelos tribunais nos casos em que transgressões à lei são descobertas e julgadas. $^{40}$

Interessante trazer à lume, ainda que de maneira parentética, que é justamente esse aspecto característico das escolas realistas o que gera um certo incômodo na compreensão do Direito. De fato, ao permitir que o Direito vigente seja, em maior ou menor medida, aquele indicado pelos Magistrados, se está abrindo uma via ampla à concessão de uma discricionariedade judicial que talvez seja indesejada.

É certo, contudo, que em Ross essa discricionariedade não é completamente ilimitada, já que é matizada justamente pelo próprio Direito posto, como se acompanha da construção de direito vigente realizada pelo autor dinamarquês.

Retomando, no que tange à significação ou objetivo do Direito, enxerga o autor que aqueles se verificam no "fato das normas jurídicas se referirem, em última análise, ao movimento dos juízes aplicarem a força, ou seja, utilizarem efetivamente as normas jurídicas produzidas pelas autoridades com competência para tanto". ${ }^{41}$

Aqui novamente se encontra um dos traços - e talvez o de maior destaque, que inclusive lhe

\footnotetext{
${ }^{39}$ ROSS, Alf. Direito e Justiça. Tradução Edson Bini. 2. ed. Bauru: EDIPRO, 2007, p. 57.

${ }^{40}$ Ibid, p. 60.

${ }^{41}$ SGARBI, Adrian. Clássicos de Teoria do Direito. 2. ed. Rio de Janeiro: Lumen Juris, 2009, p. 78.

${ }^{42}$ DELGADO PINTO, José. Sobre la vigencia y la validez de las normas jurídicas. Doxa, Alicante, n. 07, 1990. p. 120.

${ }^{43}$ Vemos aqui um ponto de aproximação entre Ross e Kelsen, já que o segundo pontifica de maneira expressa que
}

acomete a alcunha de realista - característicos da construção jurídica de Ross, para quem o direito vigente corresponderia, em amplos termos, ao direito aplicado pelos juízes.

Não é a outra a leitura que faz José Pinto Delgado sobre a obra de Ross, ao sublinhar que "un orden jurídico constituye un conjunto articulado de normas o directivas que reglamentan el uso de la fuerza por los tribunales, los hechos sociales relevantes son precisamente las decisiones de los jueces". ${ }^{4}$

$\mathrm{O}$ ordenamento jurídico é que determinará sob que condições será utilizada a coerção contra determinada(s) pessoa(s), e compete aos tribunais (juízes) executar, nos casos em que é devido, o exercício monopólico da força estatal. ${ }^{43}$

Conclui-se, assim, que a resposta à indagação inicial, que questiona como é possível distinguir o Direito de outros corpos individuais de normas, pode ser obtida observando dois pontos precípuos.

A primeira nota consiste no emprego da coerção, no exercício da força pelo Direito. É justamente a força, representada pela sanção, que atua como uma "pressão para produzir o comportamento desejado". ${ }^{44}$ O segundo ponto repousa na constituição do Direito não só pelas normas de conduta, mas também pela existência de normas de competência, que "estabelecem um conjunto de autoridades públicas para aprovar normas de conduta e exercer a força em conformidade com elas". 45

$\mathrm{Na}$ linha de todas as considerações já feitas até aqui, sobre o conceito de vigência em Ross, explica Bulygin:

"o Direito faz do uso da força um monopólio da comunidade. E, precisamente por fazê-lo, o Direito pacifica a comunidade" (KELSEN, Hans. Teoria geral do direito $e$ do Estado. Tradução Luiz Carlos Borges. 4.ed. São Paulo: Martins Fontes, 2005. p. 30).

${ }^{44}$ ROSS, op. cit., p. 85.

${ }^{45}$ Ibid, p. 85. 
Por "vigencia" Ross entiende el hecho de que la norma es efectivamente usada y aplicada por los órganos encargados de disponer del uso de la fuerza, esto es, por los tribunales y ciertos funcionarios administrativos. Por consiguiente, las proposiciones de la ciencia jurídica son empíricas, descriptivas de ciertos hechos sociales, que las hacen verdaderas. ${ }^{46}$

Derradeiramente, tendo-se já uma breve noção da estruturação do significado de direito vigente em Ross, ver-se-ão as suas implicações paradoxais com a estabilidade social.

\section{O PARADOXO DO DIREITO VIGENTE DE ROSS}

Refletindo sobre o que foi até então exposto, já se consegue, sistematizando o entendimento de Ross, vislumbrar um paradoxo aparente entre a vigência e a estabilidade de uma ordem social. Assim sendo, o paradoxo se traduz no entendimento de que "quanto mais é uma regra acatada na vida jurídica extrajudicial, mais difícil é verificar se essa regra detém vigência, já que os tribunais têm uma oportunidade muito menor de manifestar sua reação". ${ }^{47}$

Em Ross, à medida que os conflitos sociais crescem, havendo desrespeito das regras, clamando, portanto, por apreciações judiciais, mais robusto e clarividente se torna o direito vigente de determinada ordem jurídica, onde, a contrario sensu, ao passo em que há uma maior paz social, uma estabilidade nas relações sociais, menor a atuação jurisdicional e, consequentemente, mais problemática se torna a verificação do direito vigente.

Duas considerações sobre o paradoxo rossoniano merecem espaço neste texto. Primeiramente, ao contrário da imagem preconcebida de paradoxos como situações indesejáveis, incorretas ou caóticas, percebe-se

\footnotetext{
${ }^{46}$ BULYGIN, Eugenio. Alf Ross y el realismo escandinavo. Anuario de Filosofía Jurídica y Social, Buenos Aires, n. 1, 1981. p. 79.
}

que a estruturação do direito vigente como proposta por Ross, em paralelo com a estabilidade da ordem social, funciona como meio de equilíbrio, isto é, uma verdadeira balança do ordenamento jurídico.

Para os cidadãos de certa ordem jurídica, o fato do direito vigente não se mostrar com feições muito claras não acarreta nenhum agravo, uma vez que não se faz necessário neste momento a figura a reluzir do direito vigente, tendo em vista que as relações sociais se encontram, de forma ampla, em harmonia. É desinteressante ao cidadão um direito vigente plenamente visível quando suas condutas habituais se bastam por si próprias. Por outro lado, a partir do momento em que conflitos comecem a emergir com maior frequência, exigindo-se decisões judiciais contumazes, o direito vigente ocupará sua posição de realce servindo para reequilibrar o desequilíbrio social criado, permitindo que haja predições futuras das atuações jurisdicionais, sendo, neste ponto, desejável.

Nesta trilha, como assentado por Ross, "não faz diferença se as pessoas acatam a proibição ou com frequência ignoram" 48 , já que o que se deve observar é a manifestação dos tribunais. E, a manifestação jurisdicional, quando tímida por indicar uma estabilidade social, não gera prejuízo aos jurisdicionados; já quando a atuação dos tribunais se mostra frequente e necessária, aquela indica as diretivas a serem seguidas pela população, ditando condutas comportamentais.

$\mathrm{O}$ segundo ponto é que, enquanto o entendimento paradoxal de Ross sobre o direito vigente e a estabilidade social constitui algo operável e equilibrado para a população de determinado ordenamento jurídico, o mesmo não se infere para um observador externo, um outsider. Um sujeito advindo de uma ordem

\footnotetext{
${ }^{47}$ ROSS, Alf. Direito e Justiça. Tradução Edson Bini. 2. ed. Bauru: EDIPRO, 2007, p.60.

${ }^{48}$ ROSS, Alf. Direito e Justiça. Tradução Edson Bini. 2. ed. Bauru: EDIPRO, 2007, p.60.
} 
jurídica distinta, que deseja ingressar numa nova sociedade regida por um diferente ordenamento, não poderá de antemão, quando haja uma estabilidade social e, portanto, um direito vigente "enfraquecido", compreender, observando a sistemática daquela ordem, quais regras são de fato acatadas, não sendo capaz de predizer, logo, as consequências de seus atos perante à ordem jurídica. Será necessário que este sujeito externo ingresse de fato na novel ordem para, somente posteriormente, absorver as vantagens do paradoxo existente entre direito vigente $\mathrm{e}$ estabilidade social.

Calha à fiveleta sublinhar que a construção paradoxal rossoniana tem o condão de tratar o direito vigente em sintonia com um dos - e talvez o mais fundamental - escopo do Direito, qual seja, a manutenção e regulamentação da paz social. ${ }^{49}$ Afinal, a formação de um direito vigente só tem razão de ser quando se faz mister mecanismos de preservação e/ou restauração da paz. Não havendo conflitos no âmago da sociedade, um direito vigente bem delimitado e com graves contornos não se torna, à primeira vista, uma questão urgente e imperiosa.

Desta feita, vê-se que Ross, com rara felicidade, estruturou um entendimento sobre o direito vigente de forma que sua nuance paradoxal com a estabilidade social se autorregule internamente, fazendo com que a atuação jurisdicional, que consolida o direito vigente, tenha suas feições evidenciadas somente quando as regras são constantemente violadas pelos jurisdicionados, fazendo com que ambas as facetas do direito vigente - ora em evidência, ora

\footnotetext{
49 Tratando da relação entre a paz e o Direito, Kelsen declara: "Afinal, uma comunidade só será possível se cada indivíduo respeitar certos interesses - vida, saúde, liberdade e propriedade - de todos os outros, ou seja, se cada um se abstiver de interferir pela força nas esferas de interesses dos outros. A técnica social que chamamos 'Direito' consiste em induzir o indivíduo a se abster de interferência imposta na esfera de interesses dos outros através de meios específicos: no caso de tal interferência, a própria comunidade jurídica reage com uma interferência similar na
}

com características indefinidas - consigam suprir os anseios sociais.

\section{CONCLUSÃO}

Em especial em terrae brasilis, há - e sempre houve - uma forte crítica ao realismo jurídico (em qualquer de suas vertentes), não aceitando os juristas brasileiros que o Direito pudesse depender, em maior ou menor medida, da compreensão e aplicação das normas pelos juízes e determinadas autoridades administrativas, em uma espécie de "voluntarismo judicial". 50

Seguindo essa toada, a problemática que pode eventualmente ser notada não reside na forma paradoxal com a qual se estruturou o direito vigente para o autor dinamarquês, já que, como visto, figura entre nós como uma construção ímpar e que busca atender ao que se propõe, mas sim na própria conceituação de direito vigente estruturada por Ross.

Ainda que com limites impostos pelo próprio direito posto na construção de Ross, é inegável que trabalha o autor com um nível elevado de discricionariedade judicial, permitindo, por exemplo, que os Magistrados deixem de aplicar leis ainda que não se esteja diante de uma inconstitucionalidade ou uma colisão com princípios. Ou seja, na vastidão de normas jurídicas encontradas no Direito positivo, é o juiz que seleciona as que serão aplicadas e serão, assim, na visão de Ross, com as ponderações já feitas ao longo do texto, direito vigente.

esfera de interesses do indivíduo responsável pela influência prévia" (KELSEN, Hans. Teoria geral do direito e do Estado. Tradução Luiz Carlos Borges. 4.ed. São Paulo: Martins Fontes, 2005. p. 31).

${ }^{50}$ A propósito, vide STRECK, Lênio. OK, Juiz não é Deus (Juge n'est pas Dieu!). Mas, há(via) dúvida? Revista CONJUR, Brasília, 20 nov. 2014. Disponível em: $<$ http://www.conjur.com.br/2014-nov-20/senso-incomumok-juiz-nao-deus-juge-nest-pas-dieu-duvida>. Acessado em 13 jan. 2016. 
Ao adotar uma doutrina que agrega elementos do realismo comportamental e do realismo psicológico, como faz Ross ${ }^{51}$, corre-se o risco de o Direito positivo depender de um decisionismo ou subjetivismo judicial, o que, ao contrário do pretendido, que seria assegurar uma maior previsibilidade das decisões futuras, poderia acabar por instabilizar a compreensão das regras jurídicas tidas como vigentes e a coerência e integridade das decisões judiciais.

Além disso, com o escopo de não se trabalhar o Direito somente no plano ideal, que desconsideraria os aspectos reais de sua concretização, a limitação conferida por Ross a um corpo muito reduzido de atores que ditam o direito vigente, excluindo, de certa forma, a sociedade como um todo, acaba por idealizar, ainda que de maneira diversa, o Direito, funcionando também de maneira contrária à pretendida.

Mas, independentemente da posição pessoal em relação àquela escola jurídica, e cientes das inconsistências acima apontadas, certo é que Alf Ross trouxe importantes e válidas considerações jurídicas que despertam pontos até então não pensados, ou ainda que permitam uma reflexão e revisão de certo dogmas jurídicos.

O trabalho de Ross trouxe uma perspectiva curiosamente paradoxal, na qual, ainda que não seja intencional, coteja de maneira harmônica a necessidade por um direito vigente em evidência a estabilidade e paz presente em determinada sociedade, de modo a que, na ausência de um dos elementos, o outro o supre, equilibrando a balança entre o ordenamento jurídico e a vida em sociedade.

A contribuição de Ross, a nosso sentir, traz dois principais pontos de realce: o primeiro é aquele que desperta nos novos juristas a reflexão de que é possível que o trabalho do pesquisador do Direito não seja completamente abstraído do plano da realidade, ainda que o trabalho teórico demande certo fechamento hermético, podendo a pesquisa jurídica, em maior ou menor medida, sempre refletir considerações para a realidade social. $^{52}$

O segundo diz respeito ao esforço doutrinário do autor em construir uma teoria que tenta ser, na medida do possível, autossuficiente. Quando escreve sobre direito vigente, na forma vista ao longo do texto, o autor busca trazer o aspecto da vigência, muitas vezes deixado de lado nas obras jurídicas, como questão que completa por si só as lacunas do seu conteúdo, é dizer, um direito vigente com maior força ou menor força não constitui uma problemática, pois a forma como se compreende tal conceito trabalha de modo a solucionar possíveis conflitos em qualquer das hipóteses, ainda que de maneira paradoxal.

\section{REFERÊNCIAS}

BULYGIN, Eugenio. Alf Ross y el realismo escandinavo. Anuario de Filosofía Jurídica y Social, Buenos Aires, n. 1, p. 75-89, 1981.

DELGADO PINTO, José. Sobre la vigencia y la validez de las normas jurídicas. Doxa, Alicante, n. 07, p. 101-167, 1990.

\footnotetext{
${ }^{51}$ ROSS, Alf. Direito e Justiça. Tradução Edson Bini. 2. ed. Bauru: EDIPRO, 2007. p. 100.

52 “'[...] [N]ão devemos interpretar as proposições acerca do direito vigente como proposições que aludem a uma
}

validade inobservável ou 'força obrigatória' derivada de princípios ou postulados a priori, mas sim como proposições que se referem a fatos sociais" (ROSS, op. cit., p. 65). 
FRANK, Felipe; CORRÊA, Rafael. Direito e Justiça Segundo o Realismo Jurídico de Alf Ross. ANIMA: Revista Eletrônica do Curso de Direito das Faculdades OPET - Caderno de produção do corpo Docente e Discente, Curitiba, n. 13, jan./jun. 2015.

GARCIA MÁYNEZ, Eduardo. En torno de la Teoria de Alf Ross. Crítica: Revista Hispanoamericana de Filosofía, Mexico, v. 1, n. 3, p. 3-20, sep. 1967.

GOMES, Nelson Gonçalves. Um panorama da lógica deôntica. Kriterion: Revista de Filosofia, Belo Horizonte, v. 49, n. 117, p. 9-38, 2007.

HEMPEL, Carl G. Review: Imperatives and logic by Alf Ross. The Journal of Symbolic Logic, New York, v. 6, n. 3, p. 105-106, 1941.

HOLMES JR., Oliver Wendell. The Common Law. New York: Dover, 1991.

KELSEN, Hans. Teoria geral do direito e do Estado. Tradução Luiz Carlos Borges. 4. ed. São Paulo: Martins Fontes, 2005.

MACNAMARA, Paul. Deontic Logic. In: GABBAY, Dov M.; WOODS, John (Org.). Handbook of the history of logic: Logic and the modalities in the Twentieth Century - v. 7. Amsterdan: Elsevier Science \& Techonology Books, 2006.

ROSS, Alf. Direito e Justiça. Tradução Edson Bini. 2. ed. Bauru: EDIPRO, 2007.

. Imperatives and Logic. Philosophy of Science, Chicago, v. 11.1, p. 30-46, 1944.

. Logica de las normas. Tradução José S.P. Hierro. Madrid: Editorial Tecnos, 1971.

SERBENA, Cesar Antônio. Paradoxos semânticos e auto-referência normativa na linguagem jurídica. In: VII Congresso Brasileiro de Filosofia, 2002, João Pessoa-PB. VII Congresso Brasileiro de Filosofia - Anais. João Pessoa-PB, 2002. v. único. p. 356-374.

SGARBI, Adrian. Clássicos de Teoria do Direito. 2. ed. Rio de Janeiro: Lumen Juris, 2009.

. Teoria do Direito: primeiras lições. Rio de Janeiro: Lumen Juris, 2007.

STRECK, Lênio. OK, Juiz não é Deus (Juge n'est pas Dieu!). Mas, há(via) dúvida? Revista CONJUR, Brasília, 20 nov. 2014. Disponível em: $<$ http://www.conjur.com.br/2014-nov-20/senso-incomum-okjuiz-nao-deus-juge-nest-pas-dieu-duvida>. Acessado em 13 jan. 2016.

TESTA, Rafael Rodrigues. Uma análise de algumas lógicas deônticas para a representação de normas jurídicas. Campinas: Universidade Estadual de Campinas, 2006.

WAABEN, Knud. Alf Ross 1899-1979: A Biographical Sketch. European Journal of International Law, v. 14.4, p. 661-674, 2003. 
